\title{
ANALYSIS OF ENERGY PRODUCTION IN POLISH BIOGAS PLANTS - COMPARISON
}

\author{
Marta Bloch-Michalik, Marek Gaworski \\ Warsaw University of Life Sciences, Poland \\ marta_michalik@sggw.pl,marek_gaworski@sggw.pl
}

\begin{abstract}
The biogas cycle is an integrated system for the use of natural resources, disposal of organic waste, recycling and distribution of fertiliser components. Therefore, it also involves production of renewable energy, which brings both energy and environmental or even agricultural benefits. The production of agricultural biogas in Poland is becoming increasingly common year by year and the amount of biogas produced depends on more different substrates than a few years ago. Volumes of electricity produced at Polish biogas plants differ significantly from the desirable amounts. The same applies to heat. Because the amount of produced biogas depends essentially on the composition of the substrates used in practice, exact calculation is virtually impossible as a rule, because of lack of data on the concentrations of various nutrients contained in the most frequently mixed substrates. Moreover, all such computations should be performed on one hundred percent decomposed organic matter, which is impossible in practice. Nevertheless, if the amount of biogas produced is already known, all further computations become easier. Owing to the quarterly reporting obligation imposed on operators of the installations by applicable provisions of the law, we are able to analyse the presented data. This paper is based on official information provided by the Agricultural Market Agency and the authors also set themselves the goal of finding a link between the results of the Polish biogas plants and the deteriorating legislative situation of renewable energy sources in the country. Discussion concerning the results of the carried out analyses emphasizes the high biomass potential for biogas production in the Polish conditions.
\end{abstract}

Keywords: anomalies, biogas, energy, production efficiency.

\section{Introduction}

Anaerobic digestion (AD) as the process of biogas production provides a significant meaning of correlation amongthe objectives concerning energy, environmental and waste management policy. Interest in biogas is increasing in Western Europe due to a wide range of potential raw materials, as well as the interest in efficient management of biological waste and reduction of the emissions of greenhouse gases and ammonia to the atmosphere $[1 ; 2]$. The variety of raw materials and digestion processes contributes to the flexibility of biogas production systems, but at the same time, makes their analysis and comparison more complicated.

The operating pattern of biogas power plants units in the Polish legal system differs from other renewable energy sources. In the case of photovoltaic or wind farms, practically all costs are focused in the initial investment. Once installed, photovoltaic modules or wind turbines will generate energy throughout their lifetime. They do not require any investment in any fuel, and the costs of their operations are practically only related to service. Biogas plants run differently - the objects depend on a stable supply chain.

The Polish concept of RES (Renewable Energy Sources) support is a kind of "power auctions" commitment to supplying electricity at a fixed price overa long period of time. It is difficult to expect farmers to be able to predict the costs of running a farm within 15 years. For this reason, the current auction rules are mismatched, and the entire system does not encourage participation in auctions, as it carries the risk of selling electricity at prices below the production costs. It is worth mentioning that the main principle for winning the auctions is the lowest cost of energy production. At the end of 2016, only 7 biogas plants took part in power auctions and all of them managed to obtain long-term contracts for the sale of energy.

Biogas plants, biomass incineration plants and wind energy farms are the main driving force, which will allow achievement of a $15 \%$ RES share in Poland by 2020. However, both biogas plants and wind turbines face several legal problems.

The vast majority of operators of agricultural biogas plants sell their energy to the grid under the certification system. Some of them have gone into the auction system. In previous years, agricultural biogas producers, just like wind, hydroelectric or photovoltaic power plant operators, were operating at the threshold of profitability due to collapse of the green certificate market. 
The problem is that, so far, the auctions for agricultural biogas plant projects have not yet taken place and it is unknown, when they will take place, and the European Commission has raised doubts about favouring biogas plants as part of public aid for RES.

\section{Materials and methods}

As described in the Polish RES Act [3], entrepreneurs, whose business activity involves production of agricultural biogas or electricity generation from agricultural biogas, are required to register in the registry kept by the President of the National Centre of Agricultural Support (former Agricultural Market Agency - ARR; the name of the institution is own translation; the website of this institution does not have any foreign language version), providing the following data:

- amount and type of raw materials used to produce agricultural biogas or to generate electricity from biogas,

- amount of produced biogas, with specification of agricultural biogas entered into the gas distribution network, used for electricity generation in a separated or co-generation system or in a different manner,

- until mid-2015, also the amount of heat and electricity generated from agricultural biogas in a separated or co-generation system.

In the next part of the study, theoretical production values were determined and compared with actual figures. Due to the fact that in the last two years of the analysis, no information on heat production was provided, since the analysed values have a visible upward trend without periodic fluctuations, only with random fluctuations, one of adaptation methods was used for forecasting [5]. In this study, the forecast was carried out using a drift trend model with harmonic weight indicators (markers) as shown below.

$$
Y_{T}=17658.88+(T-14) \cdot 1763.29,
$$

where $T$-estimated period;

$Y_{T}$ value in the forecast period.

\section{Results and discussion}

Analysis of the official data regarding the Polish biogas plant productivity reveals low effectiveness of the biogas conversion process and raises significant doubts related to biogas production and management on the Polish market.

According to the obligatory reporting of production data, the first step in development of this paper involved basic calculations. The data below are public and available at the National Centre of Agricultural Support website.

In the discussed period, the amount of biogas produced was steadily increasing, and in 2016 it was almost seven times higher than in 2011. Biogas is mainly used as input for energy conversion (electricity and heat generation). The consumption of input energy conversion in 2016 accounted for $66.3 \%$ of the biogas produced, $33.5 \%$ for final consumption, mainly in the trade and services sector ( $25 \%$ of domestic consumption), while the energy sector's own consumption amounted to $0.2 \%$ of the biogas produced [4].

Table 1

Annual production from Polish biogas plants

\begin{tabular}{|c|c|c|c|}
\hline Year & $\begin{array}{c}\text { Annual biogas } \\
\text { production, mln } \mathbf{~ m}^{\mathbf{3}}\end{array}$ & $\begin{array}{c}\text { Annual electricity } \\
\text { production, GWh }\end{array}$ & $\begin{array}{c}\text { Annual heat } \\
\text { production, GWh }\end{array}$ \\
\hline 2011 & 36.65 & 73.43 & 82.64 \\
\hline 2012 & 73.15 & 141.80 & 160.13 \\
\hline 2013 & 112.41 & 227.88 & 246.56 \\
\hline 2014 & 174.25 & 354.98 & 373.91 \\
\hline 2015 & 206.24 & 429.40 & $225.00^{*}$ \\
\hline 2016 & 250.16 & 524.53 & - \\
\hline \multicolumn{2}{|c}{ * half-year amount }
\end{tabular}


Table 1 shows annual biogas, electricity and heat production increases, which seems obvious in connection with the growing number of new biogas plants. But, if compared with the dynamics shown in Table 2, one can notice that the growth is decreasing every year.

Table 2

Biogas production dynamics

\begin{tabular}{|c|c|c|c|c|}
\hline $\mathbf{2 0 1 2} / \mathbf{2 0 1 1}$ & $\mathbf{2 0 1 3 / 2 0 1 2}$ & $\mathbf{2 0 1 4 / 2 0 1 3}$ & $\mathbf{2 0 1 5 / 2 0 1 4}$ & $\mathbf{2 0 1 6} / \mathbf{2 0 1 5}$ \\
\hline $199.6 \%$ & $153.7 \%$ & $155.0 \%$ & $118.4 \%$ & $121.3 \%$ \\
\hline
\end{tabular}

Fig. 1 shows a confrontation between electricity and heat production at Polish biogas plants from 2011 to 2016.

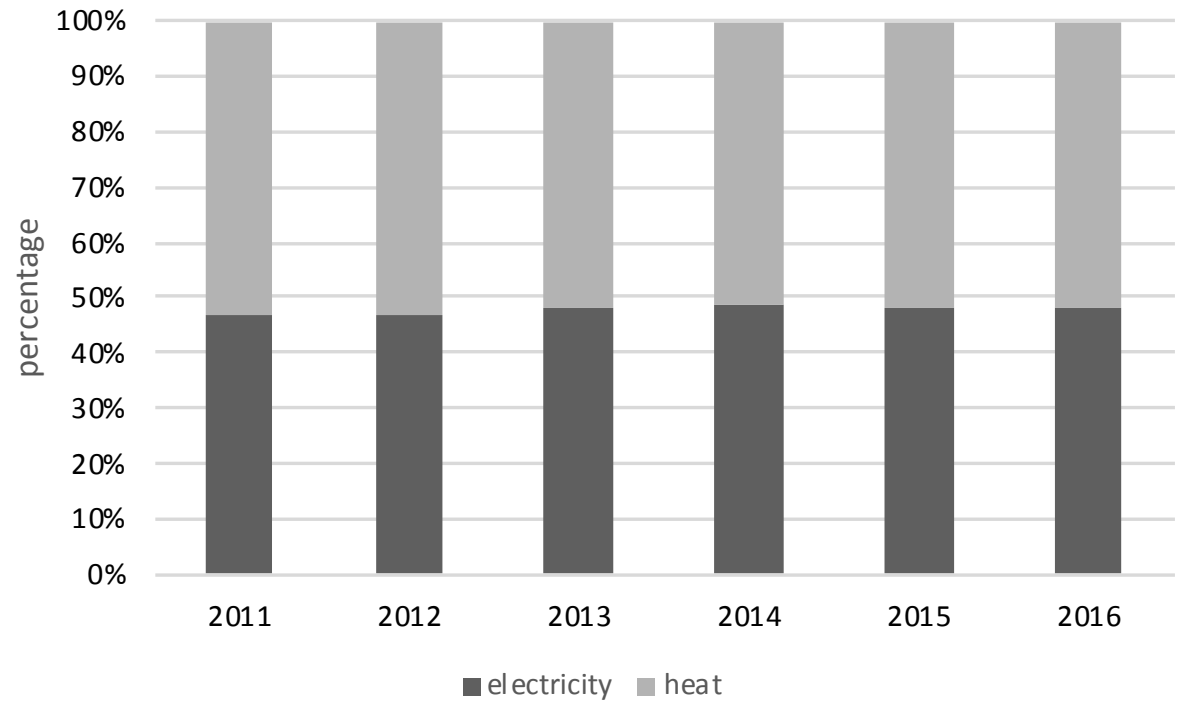

Fig. 1. Annual comparison of electricity and heat unitary production from biogas in Poland; 2011-2016

Any commercially profitable biogas plant must operate with maximum efficiency in order to obtain maximum output over the long term. Any inefficient or interrupted process can seriously affect the final results. Even at small plants with a capacity of $500 \mathrm{~kW}$ or less, any downtime easily brings about losses of several thousand euros a day [6].

Commensurate with various estimates, the content of chemical energy of biogas equals about $6.1 \mathrm{kWh}$. Based on standards for high-efficiency cogeneration, the authors assume that ca. $2.44 \mathrm{kWh}$ $(40 \%)$ of electric energy and $2.62 \mathrm{kWh}(43 \%)$ of heat are produced in the conversion process. The remaining energy output of $1.04 \mathrm{kWh}( \pm 17 \%)$ is the loss. In the subsequent parts of the present paper, these numbers are referred to as efficiency ratios [7].

Figure 2. presents the fluctuations of production efficiency of electricity and heat from biogas at Polish plants; remarkably, the numbers are not even close to theoretical values. Electricity production efficiency varies between $31 \%$ and $35 \%$ and for heat it falls within the range of 37\%-35\%. These results provide a rational premise for a more detailed analysis.

Evaluation of the estimations enabled widening of theoretical and factual biogas losses. Estimation results are shown in Table 3. The increasing trend seems to be continued due to the parallel situation with global biogas production.

Table 3

Estimation of biogas heat production

\begin{tabular}{|c|c|c|}
\hline $\begin{array}{c}\text { Year of } \\
\text { estimation }\end{array}$ & $\begin{array}{c}\text { Estimated heat } \\
\text { production, GWh }\end{array}$ & $\begin{array}{c}\text { Relative forecasting } \\
\text { error, \% }\end{array}$ \\
\hline 2015 & 458.43 & 1.47 \\
\hline 2016 & 560.00 & 1.32 \\
\hline
\end{tabular}

Low forecast errors evidence acceptability of the estimated forecasts. 


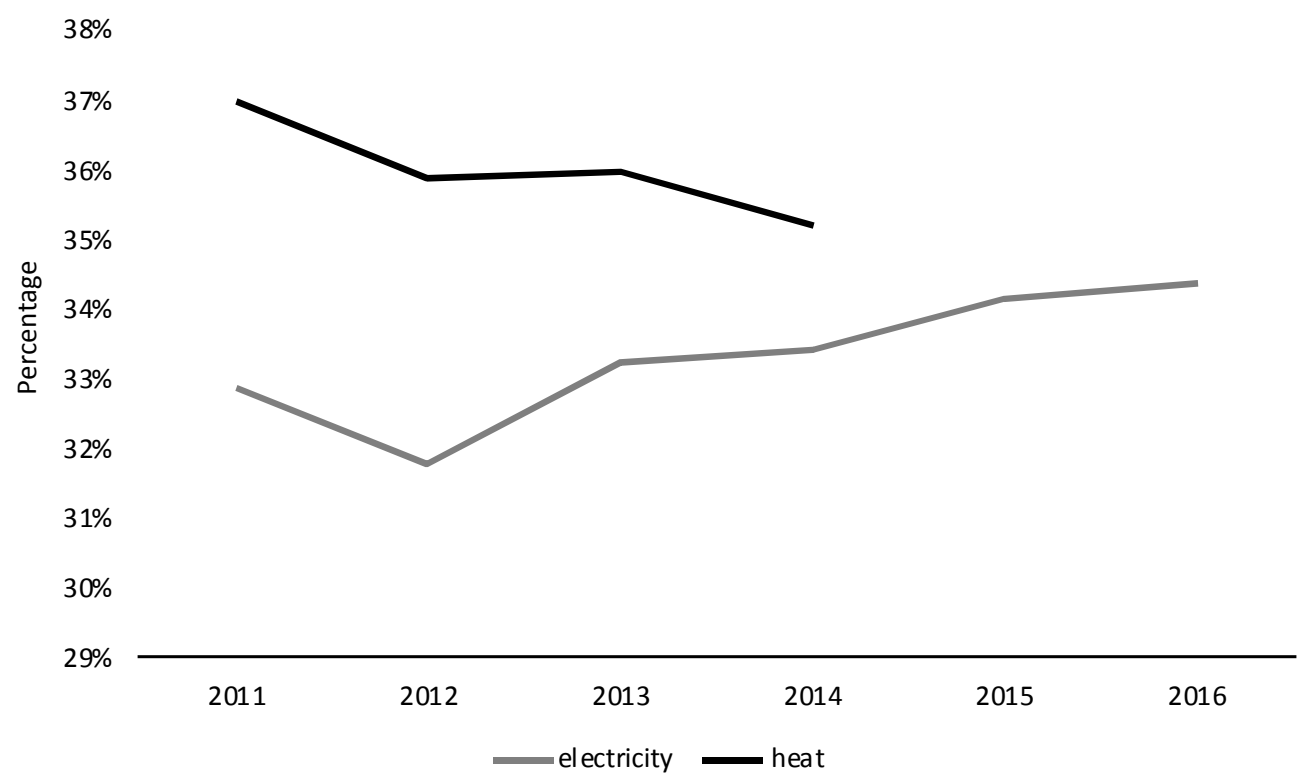

Fig. 2. Production efficiency at biogas plants

The final result, presented in Figure 3 below, indicates an increasing discrepancy between the actual and theoretical data over time. Since the methodology of determining theoretical losses for each year is the same, one can assume with a high degree of probability that biogas installations in Poland are becoming less efficient.

The reasons for this situation might be sought in the confusion surrounding the legislative order regarding renewable energy sources and their financial support in Poland. In recent years, this has been the reason for financial failure of most biogas plant operators in Poland. The discussed aspects of biogas production in Poland [8] confirm that such kind of activity includes risk, which can be integrated with political changes in dynamic modelling of biogas production [9] and the energy policy context [10] as it is shown by the example of other European countries [11].

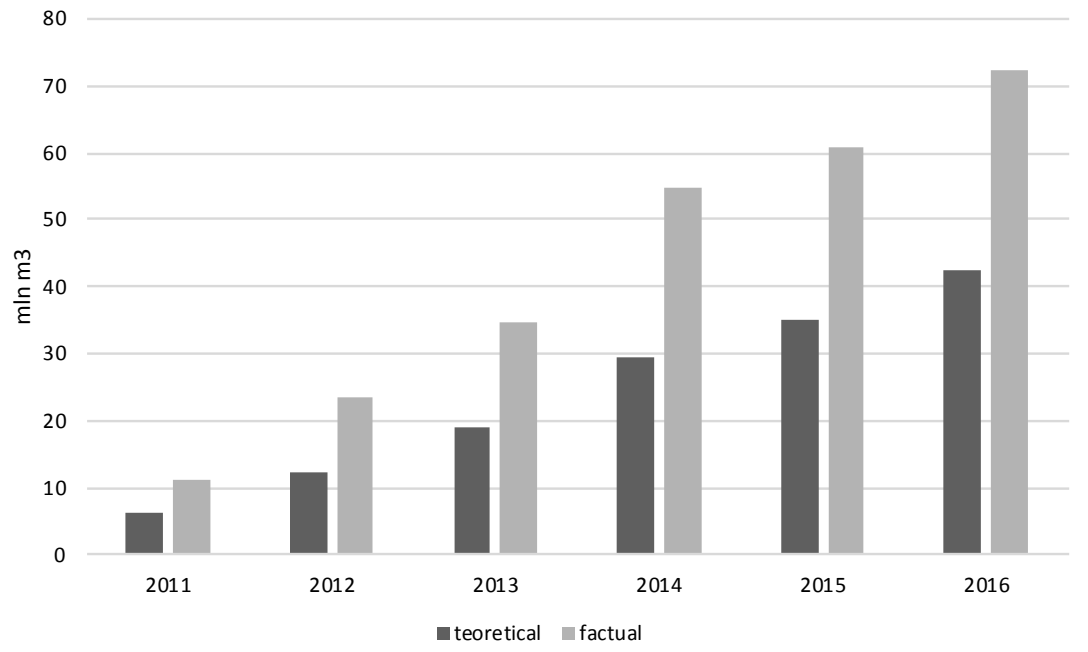

Fig. 3. Comparison of biogas theoretical and actual losses on Polish market

\section{Conclusions}

1. The volumes of electricity produced at Polish biogas plants differ significantly from the desirable amounts.

2. The reasons underlying poor results of the Polish biogas plants should constitute a premise for further analysis and deep audits of biogas operators' reports. 


\section{References}

[1] Buadit T., Aroonsrimorakot S., Bhaktikul K., Thavipoke P. Biogas Production and Greenhouse Gases Reduction from Wastewater at Mahidol University, Salaya Campus, Thailand. APCBEE Procedia, vol. 5, 2013, pp. 169-174.

[2] Angrecka S., Herbut P. The impact of natural ventilationon ammonia emissions from free stall barns. Polish Journal of Environmental Studies,vol. 23(6), 2014, pp. 2303-2307.

[3] Act of 20 July 2017 amending the Act on Renewable Energy Sources.

[4] Statistics Poland. Energy from renewable sources. Warsaw: Statistics Poland (in Polish).

[5] Mularczyk A. Analysis of production the electricity from renewable energy sources in Poland. Zeszyty Naukowe Politechniki Śląskiej. Organizacja i Zarządzanie,z.96, 2016, pp. 133-142 (in Polish).

[6] GebrezgabherSolomie.Economic analysis of anaerobic digestion - A case of Green power biogas plant in The Netherlands. NJAS -Wageningen Journal of Life Sciences, vol. 57, Issue 2, June 2010, pp. 109-115.

[7] Bloch-Michalik M., Gaworski M. Anomalies in energy production in Polish biogas plants. Annalsof WarsawUniversityof Life Sciences-SGGW, Agriculture,No. 68, 2016, pp. 75-80.

[8] Sobolewski. M. Increasing the usage of renewable energy sources in Poland. Studia BAS, vol. 1(21), 2010, pp. 267-290 (in Polish).

[9] Zeverte-Rivza S., Pilvere I., Rivza P. Integration of risks and political changes in dynamic modelling of biogas production. Proceedings of the International scientific conference "Engineering for Rural Development 2014", Latvia University of Agriculture, Faculty of Engineering, vol. 13, 2014, pp. 541-546.

[10] Szurlej A., Mirowski T., Kamiński J. An analysis of changes in the power generation fuel-mix: the energy policy context. Rynek Energii, vol. 1, 2013, pp. 3-10 (in Polish).

[11]Putek-Szeląg E., Gierałtowska U. Analysis and diagnosis of the volume of renewable energy production in Poland compared to EU countries. [In:] Jajuga K., Walesiak M. (eds.): Taksonomia 21. Klasyfikacja i analiza danych. Prace Naukowe Uniwersytetu Ekonomicznego we Wrocławiu, vol. 279, 2013, Wrocław (in Polish). 